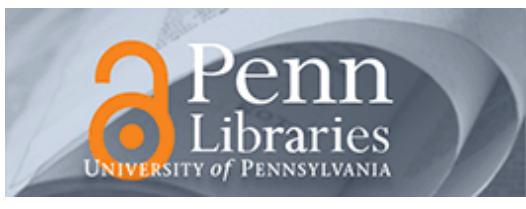

University of Pennsylvania
ScholarlyCommons

Departmental Papers (ASC)

Annenberg School for Communication

1990

\title{
Where is the Author in American TV News? On the Construction and Presentation of Proximity, Authorship and Journalistic Authority
}

Barbie Zelizer

University of Pennsylvania, bzelizer@asc.upenn.edu

Follow this and additional works at: https://repository.upenn.edu/asc_papers

Part of the Broadcast and Video Studies Commons

\section{Recommended Citation}

Zelizer, B. (1990). Where is the Author in American TV News? On the Construction and Presentation of Proximity, Authorship and Journalistic Authority. Semiotica, 80 (1-2), 37-48. https:// doi.org/10.1515/semi.1990.80.1-2.37 


\title{
Where is the Author in American TV News? On the Construction and Presentation of Proximity, Authorship and Journalistic Authority
}

\author{
Disciplines \\ Broadcast and Video Studies | Communication | Social and Behavioral Sciences
}




\section{Where is the author in American TV news? On the construction and presentation of proximity, authorship, and journalistic authority}

BARBIE ZELIZER

In the decade or so since the ideological effect of news and current affairs reporting was first so named (Hall 1977), studies in communications research have focused in different ways upon the authorship of broadcast news. Generally, these studies have linked questions of authorship with questions of journalistic authority, exploring the interaction beween the two via considerations of journalistic norms (Golding and Elliott 1979; Molotch and Lester 1974; Roshco 1975; Tuchman 1978; Gans 1979; Carey 1986; Cohen and Young 1973; Fishman 1980; Bennett et al. 1985); conventions of news presentation (Hartley 1982; Fiske and Hartley 1978; Kress 1986; Smith 1985; Stam 1983; Glasgow University Media Group 1980, 1976; Gibson 1979-80); or known audience effects (Morley 1980; Elliot 1982; Capo 1985; Knight and Dean 1982). In each case, a journalist's authority is used to explain how journalists take responsibility for the stories they create and tell.

To a large extent, this link between authorship and authority emerges from some underlying sense of a journalist's proximity to the event. As the executive of one American broadcasting network said long ago, journalists convey a sense that whatever the event, 'they were there', and that the story they bring to audiences 'is their own' because they 'saw' it happen. In this paper, I explore the link between journalistic authority, authorship, and proximity in American broadcast news presentation. Three questions are central here: How do American journalists create a sense of proximity for the events they cover? How is this used to convey a sense of authorship? And how is the construction of proximity and authorship used to enhance journalistic authority in the presentation of American broadcast news?

\section{'Proximity' as a given in journalistic performance}

Proximity, or a sense of 'nearness' to the events reporters cover, is built into the canons of journalistic practice (i.e., Galtung and Ruge 1965). 
These canons maintain that journalists must be sufficiently close to new stories that they can act as 'eyewitnesses', and that much of the legitimacy which audiences grant journalism is derived from a need to see event through 'mediated witnesses' (Gross 1985).

In American television news in particular, the 'eyewitness' story format is a familiar one. It emerged generally from local news set-ups, in which large teams of on-the-spot reporters gave news stations the ability to simultaneously break a number of news stories in a number of different locations. Today, most American news stations employ eyewitness for mats for certain types of stories:

The reporter usually stands in front of the building or scene in question, his heal and torso many times larger on the screen than the physical objects and person involved in the actual events being reported. Throughout the report, the actud occurrences are like putty in his masterful hands. He cuts from one shot th another; he stops the President in mid-sentence; he 'voices, over' images of kings .... (Weaver 1981: 287-288)

By being proximate to events, journalists accomplish the first step it assuming responsibility for their stories and in reporting 'what they see' in reliable and authoritative fashion (Roshco 1975; Gans 1979). By promotin their proximity, journalists can both claim authorship and establist authority for their stories. Proximity thus acts as a mitigating factor in the journalistic selection, formation, and presentation of a news story.

In the United States, however, the spatial proximity of journalists to the events they cover is becoming increasingly difficult to maintain. Whilk journalists continue to treat every event as if it were happening down the street, in actuality news stories rarely reflect a journalist's physical nearness. ${ }^{1}$ Advanced technology has made rapid information transfer possible through satellite relays or wire services, and many journalists rely as much (if not more) on these second-hand modes of informationgathering as on the 'hands-on' practices of the past. Similarly' news organizations often use stringers 'to fill the gaps left uncovered by bureaus' (Gans 1979: 124-125) or depend on sources to create the event for them (Sigal 1973; Strentz 1978; Burgess 1985). In a sense, then, journalistic proximity emerges as much from organizational practices which lend an illusion of proximity as from the actual nearness of a journalist to an event.

But it is not only organizational practices that create an illusion of proximity. The fact that most journalists continue to maintain a belief in proximity as a value for good news coverage suggests that they might rely on other means to construct a sense of nearness to their stories. Indeed, one of the more fashionable forms of televised journalistic performances in 
America - the news magazine - is built upon an understanding that the news story has been physically divorced from its storyteller (Carey 1986). This suggests a role played by presentational practices in the construction of journalistic proximity, authorship, and journalistic authority. In this paper I explore how American broadcast journalists employ spatial practices in the presentation of news as a means of creating a sense of journalistic authority for the events they cover. In other words, how do American broadcast journalists use presentational devices to create a sense of proximity in cases where it is missing from a news story's formation? While the emphasis here is on American broadcast journalists in general, this paper also considers the relevance of journalistic presentational practices in other broadcasting systems. Similarly, it focuses implicitly on the role played by the anchorperson/announcer, who, by virtue of being the most visible emblem of journalistic authority in American television news, is often left responsible for contextualizing, explaining, and backgrounding the stories which constitute the news. How central is proximity to the provision of background? When proximity is lacking in the formation of a news story, is it emphasized in its presentation? In cases in which journalists have not conveyed a sense of their own proximity, do anchorpersons provide it for them? And finally, how does this affect journalistic authorship, and the authority that emanates from it?

In order to explore these questions, the presentational practices used on a number of evening news programs on American network television (CBS and NBC) were examined for one week during the autumn of 1987. Presentational practices relating to the construction of proximity were considered first, with secondary attention being paid to those which involved anchorpersons. During the time-period under question, NBC broadcast its evening news program from China. This offered a background for analysis contrasting with that of CBS, which, as under normal circumstances, continued to broadcast from New York. It was hoped that these two contrasting venues would clarify the relevance of place and the importance of its establishment. The fact that the CBS newscast was broadcast against largely familiar settings, and NBC against unfamiliar ones, would allow for differences to emerge in the presentational practices used by journalists in establishing their proximity to events.

\section{The establishment of proximity}

In the collection and selection processes which transform events into news (i.e., Cohen and Young 1973), two senses of 'news-place' are established by newspeople en route to the presentation of broadcast news: 
(1) Place of event - this constitutes establishing a sense of place for the actual news story ('A fire today ravaged Los Angeles').

(2) Place of reporter (covering the event) - this involves establishing where the journalist is in relation to a given event ("This is Tom Brokaw. In Beijing').

Once these two senses of place are established in the selection and formulation of news, a third sense comes into play in its presentation:

(3) Place of broadcast - this involves establishing the spatial focal point of the newscast through the anchorperson/announcer. By assigning a point of perspective to the anchorperson/announcer who covers the reporter, who in turn covers the event, news organizations give audiences a point through which to gauge both the reporters covering the various items and their own perspective on the newscast. ('NBC Nightly News, with Tom Brokaw. Tonight, a special edition: A changing China'). As the Glasgow University Media Group noted, the announcer or anchorperson is 'a vehicle for articulating a text which has several sources' (1980: 131).

A number of studies have already dealt with the spatial practices located at the interface between (1) and (2), connecting place of event with place of reporter (Brooker-Gross 1985; Gerbner and Marvanyi 1977; Walmsley 1980; Burgess and Gold 1985). The long-standing reliance on the 'lead' of a story, in which the 'where' must be communicated along with the 'how, why, what, when, and who' (i.e., Bittner and Bittner 1977), has evolved into a conversation of place orientation. Each news story thus begins with a sense of place, and it is up to each journalist to align him- or herself in some way with the sense of place that has been communicated. As Sigal says, "what journalists know depends to a considerable extent on whom they know, which, in turn, depends on where they are' (Sigal 1973: 46).

Generally, the establishment of spatial placement is accomplished through datelines and headlines, which allow news institutions to estab. lish the authority of a news report (Hallin 1986). This suggests that reporters establish authorship and communicate a sense of their own place through that of the event. Thus, in the best of cases, authorship is established vis-à-vis a relatively 'real' spatial connection between reporter and event. This both tells audiences where a reporter is (the abovementioned interface between [1] and [2]) and allows them an approach to news stories through the reporter's temporal and spatial viewpoints (Schudson 1986).

Yet, as suggested earlier, this 'real' spatial connection often cannot be established, and the proximity between reporter and event must be refracted through certain presentational practices incorporated in the broadcast of news. Sometimes these practices are incorporated by the 
reporters themselves. Often, they are provided by the anchorpersons or announcers. In all cases, they serve to establish an 'on-site' presence between some member of the news organization and the event it is reporting. Of interest here are those cases which constitute invalid or fictitious accounts of where the reporter is, and which convey instead where the news organization would like him or her to be: for example, an item on then-Presidential candidate Michael Dukakis's campaign machinery in Boston begins with a visual slug entitled 'Boston'. It is only at the end of the item that audiences learn that the reporter relaying the item is in fact situated in Washington, DC, far from Boston, Massachusetts. But by the time they hear mention of another locale ('Lesley Stahl. CBS News. Washington'), the place of the event itself is already firmly entrenched.

There appear to be six main sets of presentational practices through which journalistic proximity to an event is established: ${ }^{2}$

(A) Visual keyings which establish 'place of event'/ place of reporter'. A sense of place can be communicated visually in one of two ways, both via 'slugs'. One type of slug communicates either the journalist's proximity to an event or the event's actual placement, at the beginning of the news item from the upper left-hand corner of the screen (i.e., 'Boston' or 'Capitol Hill'). A second type of slug is positioned at the end of the item, usually at the bottom of the screen. It conveys both the name of the reporter and the beat ('Bill Plante. White House Correspondent'). Slugs such as these constitute ways for a network or news organization to anchor both the 'place of event' and the 'place of reporter' for viewers in a post-facto fashion, usually in cases in which the reporters themselves have not done so. In other words, visual keyings of proximity are implemented at the presentational level, but generally not by the journalists themselves.

(B) Verbal keyings which establish 'place of reporter'/'place of event'. The proximity of journalists to events, as well as the event's positioning, can also be conveyed verbally. An anchorperson or reporter delineates 'where the event is': ('In Washington today, President Reagan confronted ...). The proximity of journalists to events is established in two basic ways: anchorpersons/announcers can verbally introduce reporters in a way which makes explicit the latter's spatial placement ('Bill Plante is in Washington with more details'); reporters can verbally give their own affiliation and 'place' ('Bill Plante. CBS News. The White House'). Verbal keyings of proximity are thus provided either by 'on the spot' reporters or by anchorpersons.

(C) Visual/verbal keyings which combine 'place of reporter' and 'place of event'. Here, various references to place come together in ways which reinforce one sense of place for both events and the reporters who cover 
them. A visual slug tells audiences that the item to follow is from, say, the White House. A second visual slug explains that the item is reported by 'Chris Wallace. The White House'. Finally, a verbal overview concludes that the item was authored by 'Chris Wallace. NBC News. At the White House'.

In many cases, a certain degree of 'place literacy' is assumed fot viewers: one item begins with a visual slug (Capitol Hill), and ends with both a different visual slug (White House correspondent) and a verbal overview ('The White House'). Yet it never specifically mentions that the item is located in Washington, DC, presuming instead that viewers know that both Capitol Hill and the White House are located in that city.

Sometimes the 'place of reporter' is used as a more specific angle for the 'place of event'. A story on gun deaths in Florida is introduced with graphics which proclaim that the story is about the 'Florida Gun Law', This is followed first by a visual slug with no place notation (Juan Vasquez. CBS News), and then by a verbal overview denoting the "place of reporter' ('Juan Vasquez. CBS News. Miami'). Similarly, a news item on migrant workers in the state of Washington is concluded with a verbal overview denoting the reporter's placement ('David Dow. CBS News. Yakima, Washington'). By so combining the 'place of event' with the 'place of reporter', journalists instill in viewers an assumption of equivalence between the two senses of place.

(D) Visual/verbal keyings which substitute 'place of event' for 'place of reporter'. A reliance on viewer equivalence between 'place of reporter' and 'place of event' sometimes allows journalists to exclude references to the former, on the assumption that viewers will assume that the two senses of place are the same. In other words, in certain cases, the 'place of event' is allowed to carry over for the 'place of reporter'. An item is introduced verbally with no place identification ('CBS National Affairs Reporter Lesley Stahl reports'); it is followed by a visual slug communicating one sense of place (Boston); and the report is concluded by another visual slug which says nothing about the 'place of reporter' ('Lesley Stahl. National Affairs Correspondent'). Only then does a verbal overview establish the 'place of reporter' as being different from that of the 'place of event' ('Lesley Stahl. CBS News. Washington'). Another item originally identified as being from Irving, Texas similarly reveals only at the end of the item that the reporter is actually elsewhere ('Harry Smith. CBS News. Dallas'). What this does is cater to viewer assumptions that wherever the event is, there lies the reporter. In broadcast news, however, this is not necessarily the case. The substitution of the 'place of event' for the 'place of reporter' allows audiences to assume greater journalistic proximity, and hence authority, for the event than the reporter actually has. 
This kind of keying for proximity also reinforces the validity of 'longdistance' observation, a common technique in American television news, by which the anchorperson or reporter discusses and reports on events which are situated at some distance from him or her. 'Long-distance' observation introduces a disjunction between where a reporter/anchorperson/announcer is and what he or she sees. It is a technique that is used so often in 'live' television coverage that it has become a distinct apparatus of most kinds of televised news performances in America and elsewhere (i.e., Feuer 1983).

(E) Visual/verbal keyings which substitute 'place of reporter' for 'place of event'. Similarly, an assumption of equivalence between 'place of reporter' and 'place of event' allows journalists to exclude references to the 'place of event'. 'Place of event' is either not given at all or is delayed until the end of the item. For instance, a story on AIDS Awareness Month is introduced without any indication of pläce ('CBS News Medical Correspondent Susan Spenser reports'). A visual slug later reinforces this information (Susan Spenser. Medical Correspondent); yet it is only at the item's end that audiences are given a verbal overview which tells them the reporter's (and, by deduction, the event's) placement ('Susan Spenser. CBS News. Washington'). The delayed identification of the reporter's placement deflects attention from the fact that the 'place of event' has never been identified. It also reinforces the assumption that the event's placement is the same as that of the reporter. Sometimes, however, this is not the case, and this constitutes one way of masking the legitimacy of journalistic claims of authorship and authority.

(F) Visual/verbal keyings which split proximity. Yet another type of practice involved in the establishent of proximity is characterized by the spatial dispersion of the text and dissipated authority of collective authorship. This is achieved by a shared screen, in which the newscast presentationally 'splits' proximity to the event. One NBC item displays two pictures and two slugs, both shown in the lower left hand corner of their respective screens: (Tom Brokaw. China/Ken Bode. Washington, DC). While this duplicates the familiar televised form which often brings American audiences an in-studio team of anchorperson and reporter, here it allows the news organization to conceal or blur 'who is where': it incorporates the localization of film clips, by using a 'local' presence as evidenced by the additional byline or face. That this practice possesses distinct organizational advantages should be obvious: consider the novice reporter who is 'distantly' located but has no information. His or her shared byline with a senior reporter at home allows the latter to apply his or her own expertise to a byline that appears more authoritative because it is 'distantly' datelined. A shared screen on television blurs 'which' of the 
participating parties deserves to be credited with the authority for the news report. The possibility of inserting an 'adjunct' reporter besides as existing one, and thus bolstering a potentially feeble journalistic perfor mance, is an appealing way for news organizations to resolve situations it which an anchorperson/reporter is located in the right place but has little to say. Conversely, it also resolves situations in which the anchorperson has much to say but is in the wrong place in which to say it.

\section{Establishing proximity by default}

Together with the various practices mentioned above, the 'place of event' and 'place of reporter' are often not established at all. When are they not indicated? Generally, this occurs at the beginning of a newscast: ('Good evening: This is the CBS Evening News. Dan Rather reporting'). The assumption here is that audiences know where the broadcast is taking place. That is, when reporters and/or anchors are situated within the studio, their placement does not require elucidation. The establishment of the 'place of broadcast' thus serves as one default case of place formulation

This happens in a number of ways. Reporters are said to be 'here' in the studio, without 'here' necessarily being explained: CBS News mentions that 'Bruce Morgan is here with the FBI story'. Often, identification of the 'place of reporter' is delayed until the end of the story, when it is then made clear that the reporter is sitting in the studio. Alternatively, the verbal overview which concludes the item is substituted by a visual shot of the reporter in the studio. The unspoken given in all of these cases is that the 'place of broadcast' does not need elucidating.

NBC coverage provides a particularly good example of this default case of place formulation during its coverage of China. There, NBC incorporated constant references to the 'place of broadcast'. They identified it within the logo ('Changing China'); via visual slugs (Shanghai), which were repeated each time the anchorperson came on the screen; and via verbal indications by the anchorperson ('Good evening from Shanghai'). These verbal indicators were also repeated each time the anchorperson came back on the screen, suggesting, in contrast to regular newscasts aired from either Washington or New York City, a need to offset standardized audience expectations concerning the 'place of broadcast'.

In this case, 'place of broadcast' needed elucidation precisely because the broadcast emanated from a different place. Reliance on China as a backdrop thus constituted an attempt to neutralize a setting that is not neutral for most Americans. In a sense, this reduced the 'place of broadcast' to the status of a regular news item. 
What this suggests is a need in certain cases for 're-identification' of place. An unspoken given in television news is the fact that places in the news do not need to be repeated if they have already been introduced to viewers during the newscast. The repeated formulation of 'place of broadcast' here suggests that 're-identification' activities are needed so as to offset unspoken assumptions among viewers about the 'place of broadcast'. The need for 're-identification' also has direct bearing on the anchorperson's performance: NBC anchor Tom Brokaw repeatedly gestures towards the setting behind him (normally not a given in regular broadcast news) and interacts with it in other ways. He also displays a certain fluidity of his own role with that of the reportorial role. After introducing the broadcast in his role of anchorperson, he turns his head slightly and dons the reportorial role: 'Recently, I went to Tibet to report on this complex and controversial situation'.

Yet another default case of place formulation emerges via global stories which appear to transcend a sense of place. To an extent, this is characteristic of all contemporary news presentations, in that the news has evolved as a collection of stories from a limited list of locations (Epstein 1973; Golding and Elliott 1979; Gerbner and Marvanyi 1977). In the majority of cases, these emerge from Washington, DC, where most American government agencies, agents, and actions are located. As mentioned earlier, this calls upon a certain degree of 'place literacy', in which the placement of certain kinds of stories is not made evident on the assumption that they do not need to be made so. Often, the 'place of event' is equated with an institution (i.e., Congress or the State Department), and revolves around governmental actions that take place therein. These include items on Reagan's reaction to Bob Woodward's book on the CIA, the American boycott of Iranian goods, unemployment, or the commodities-linked index. The 'place of event' in each of these items is not made explicit. It may thus be that institutional places of this type constitute 'ideological pockets' of a sort - they constitute the type of place or venue through which ideology does not need to be made explicit for American audiences.

\section{Conclusion: Where is the author in TV news?}

Existing literature on proximity in journalistic practice discusses journalists' reliance on it as a value used in the formation of news stories (Golding and Elliot 1979; Cohen and Young 1973). The discussion of the preceding pages suggests that, in addition to this reliance in early stages of news-gathering, American journalists construct a sense of proximity at 
stages other than news formation. It suggests that a sense of proximity emerges not only from physical codes delineating a journalist's nearnes to the stories he or she covers, but from a combination of physical organizational, and presentational codes as well. Regardless of the actual proximity of reporter to event, these codes are employed by Americal journalists to construct a sense of nearness between themselves and events. In this way, they convey to audiences a sense of authorship and authority for the stories they cover.

This suggests that American broadcast journalists transform proximity from a value into a practice. Such a notion follows earlier research on objectivity (Tuchman 1973; Molotch and Lester 1974; Sigelman 1973), accuracy (Carey 1986; Tuchman 1974), and neutrality (Roshco 1975 Fishman 1980; Tuchman 1978), all of which trace the ways in which values become practices through work routines. Unlike that research however, this paper suggests that proximity may be most centrall! realized through spatial codes used in the presentation (not formation) of news. The emphasis on presentational codes here, coupled with the stylistic advances characteristic of recent TV news programs, suggests : need for further research on the ways in which journalists might consciously use presentational devices to promote an illusion of their ow adherence to journalistic norms. Specifically, there is a need to conside how different presentational practices might be used by journalists in other broadcasting systems, in other countries.

Nonetheless, the exploratory material contained in these pages suggest that news of all kinds and creeds emerges as an endeavor of collective authorship. In much the same way that proximity is a practice employed not only by on-the-site journalists, but by in-studio journalists, anchorper sons/announcers, and news organizations as well, the authorship of television news also appears to result from collective practices. What this is turn suggests about the establishment of journalistic authorify has dired bearing on the structure of news in society: if the authority of journalist constitutes a collective code of behavior, practiced not only by individual journalists but by collective news organizations, there may be a need to redefine the ways in which the normative practices of journalists actualli operate within the larger social setting of which they are a part.

\section{Notes}

1. Journalists do run the risk of becoming too 'proximate' to events. NBC producer Reuven Frank has said that "the key to professional journalism is in the newsperson remainim an outsider: "News is seen by an outsider (the correspondent) on behalf of other outsiders (the audience)"' (Epstein 1973: 27). One way in which to offset excessive 
proximity is via the growing emergence of 'specialists', which helps to limit proximity by pre-determined boundaries of topic (Gans 1979). Yet even here there are problems. As Gans quotes one producer: 'If a reporter is too close to a subject, he is considered an expert. He does the audience no good, for he is too far away to communicate with it' (1979: 143).

2. . To an extent, the anchorperson's proximity to the event is relevant to the more general establishment of journalistic proximity because the elements of the broadcast news program (as opposed to printed news) typically form a unified whole (Weaver 1981). It is thus possible for proximity to be transformed into a spatial code that is embodied by the anchorperson. No such possibility exists with newspaper news.

\section{References}

Bennett, Lance, Gressett, Lynne A. and Haltom, William (1985). Repairing the news: A case study of the news paradigm. Journal of Communication 35 (2), 50-68.

IBittner, J. and Bittner, D. (1977). Radio Journalism. New Jersey: Prentice-Hall.

I Brooker-Gross, Susan (1985). The changing concept of place in the news. In Geography, the Media and Popular Culture, J. Burgess and J. Gold (eds.), 63-85. New York: St. Martin's Press.

Burgess, J. (1985). News from nowhere: The press, the riots and the myth of the inner city. In Geography, the Media and Popular Culture, J. Burgess and J. Gold (eds.), 192-228. New York: St. Martin's Press.

Burgess, J. and Gold, J. (eds.) (1985). Geography, the Media and Popular Culture. New York: St. Martin's Press.

Capo, James (1985). Normative issues for news as cultural celebration. Journal of Communication Inquiry 9 (2), 16-32.

Carey, James W. (1986). The dark continent of American journalism. In Reading the News, K. Manoff and M. Schudson (eds.), 146-196. New York: Pantheon Books.

Cohen, Stanley and Young, Jock (eds.) (1973). The Manufacture of News. London: Constable.

Elliott, Philip (1982). Media performances as political rituals. Communication 7, 115-130. Epstein, Edward J. (1973). News From Nowhere. New York: Random House.

Feuer, Jane (1983). The concept of live television: Ontology as ideology. In Regarding Television, E. Ann Kaplan (ed.), 12-21. Los Angeles: American Film Institute.

Fishman, Mark (1980). Manufacturing the News. Austin: University of Texas Press.

Fiske, John and Hartley, John (1978). Reading Television. London: Methuen.

Galtung, Johan and Ruge, Mari (1965). The structure of foreign news. Journal of International Peace Research 1, 64-90.

Gans, Herbert (1979). Deciding What's News. New York: Pantheon Books.

Gerbner, George and Marvanyi, P. (1977). The many worlds of the world's press. Journal of Communication 27, 52-66.

Gibson, William (1979/80). Network news: Elements of a theory. In Social Text 1-3, 88-111.

Glasgow University Media Group (1976). Bad News. London: Routledge and Kegan Paul. -(1980). More Bad News. London: Routledge and Kegan Paul.

Golding, Peter and Elliott, Philip (1979). Making the News. London: Longman Books.

Gross, Larry (1985). Life vs. art: The interpretation of visual narratives. Studies in Visual Communication 11 (4), 2-11.

Hall, Stuart (1977). Culture, the media and the 'ideological effect'. In Mass Communication 
and Society, J. Curran, M. Gurevitch, and J. Woollacott (eds.), 315-348. Beverly Hills CA: Sage Publications.

Hallin, Daniel (1986). Cartography, community and the cold war. In Reading the News, R. Manoff and M. Schudson (eds.), 109-145. New York: Pantheon Books.

Hartley, John (1982). Understanding News. London: Methuen.

Knight, Graham and Dean, Tony (1982). Myth and the structure of news. Journal d Communication 32 (2), 144-161.

Kress, Gunther (1986). Language in the media: The construction of the domains of publi and private. Media, Culture and Society 8 (4), 395-420.

Molotch, Harvey and Lester, Marilyn (1974). News as purposive behaviour. American Sociological Review 39, 101-112.

Morley, Dave (1980). The Nationwide Audience. London: British Film Institute.

Roshco, Bernard (1975). Newsmaking. Chicago: University of Chicago Press.

Schudson, Michael (1982). The politics of narrative form: The emergence of new conventions in print and television. Daedalus 3 (4), 97-112.

- (1986). Deadlines, datelines and history. In Reading the News, R. Manoff and M Schudson (eds.), 79-108. New York: Pantheon Books.

Sigal, Leon (1973). Reporters and Officials. Lexington, MA: D. C. Heath.

Sigelman, Lee (1973). Reporting the news. American Journal of Sociology 79 (1), 132-151. Smith, Susan J. (1985). News and the dissemination of fear. In Geography, the Media an' Popular Culture, J. Burgess and J. Gold (eds.), 229-253. New York: St. Martin's Press. Stam, Robert (1983). Television news and its spectator. In Regarding Television, E. An Kaplan (ed.), 23-43. Los Angeles: American Film Institute.

Strentz, Herbert (1978). News Reporters and News Sources. Ames: lowa State University Press.

Tuchman, Gaye (1973). Objectivity as a strategic ritual. American Journal of Sociology 7 (4), 660-679.

-(1974). Making news by doing work. American Journal of Sociology 79 (1), 110-131.

-(1978). Making News. Glencoe, IL: The Free Press.

Walmsley, David (1980). Spatial bias in Australian news reporting. Australian Geographer 14, 342-349.

Weaver, Paul (1981). TV news and newspaper news. In Understanding Television, Richard Adler (ed.), 277-293. New York: Praeger Publishers.

Barbie Zelizer (b. 1954) is a doctoral student at the Annenberg School of Communications in Philadelphia, Pennsylvania. Her principal research interest is in the junction between mass media, journalistic performance, folklore, and semiology. She is presently completing her dissertation on journalistic authority and recollections of the John F. Kennedy assassination. She is a co-author, with Itzhak Roeh, Elihu Katz, and Akiba Cohen, of Almost Midnight: Reforming the Late-Night News (1980). 